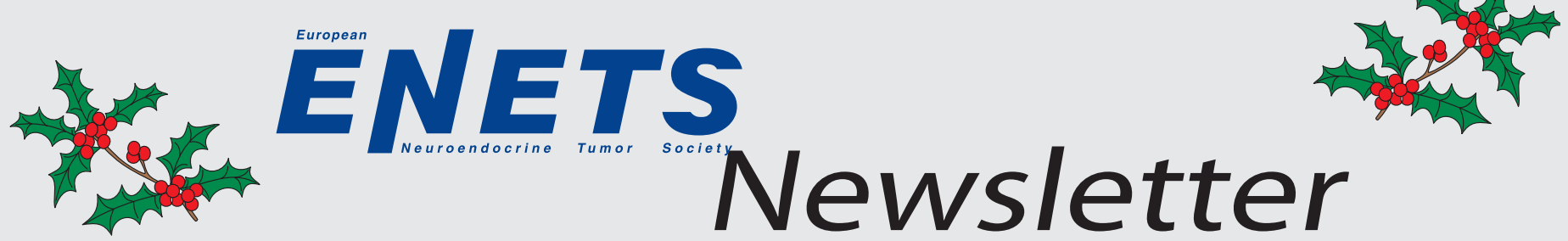

A Newsletter for Medical Professionals and ENETS Members

The European Neuroendocrine Tumor Society (ENETS)

Executive Committee:

Chairman: Bertram Wiedenmann, Berlin, Germany

Vice-Chairman: Guido Rindi, Parma, Italy

Treasurer: Ursula Plöckinger, Berlin, Germany

Chairman Elect: Wouter W. de Herder, Rotterdam, The Netherlands

Scientific Secretary: Martyn Caplin, London, UK

Members: Barbro Eriksson, Uppsala, Sweden,

Philippe Ruszniewski, Clichy, France

ENETS Newsletter Editing:

Research and Conference Coordinator: Malgorzata Szott-Emus

Scientific Editor: Ulrich-Frank Pape

English-Language Editor: Elizabeth Zach

Layout and Publishing: Karger Publishing, Basel, Switzerland

ENETS Coordinating Office:

Charité Universitätsmedizin

Campus Virchow-Klinikum

Department of Gastroenterology and Hepatology

Augustenburger Platz 1

D-13353 Berlin, Germany

Tel. +49 30450553096

Fax +49 30450553942

E-Mail enets.office@charite.de

\section{In this issue:}

Consensus Conference on the ENETS Guidelines for the Diagnosis and Treatment of Neuroendocrine Gastrointestinal Tumors:

Improving the Society's first publication

Meet the New Chairman:

An interview with Wouter W. de Herder, ENETS Chairman Elect

\section{Letter from the ENETS Chairman}

Before all else, I would like to take this opportunity to wish all of you the best of holiday greetings. I wish you, too, a prosperous and healthy new year.

In thinking about 2006, I would like to remind you that the deadline to register for the 3rd Annual ENETS Conference is 31 December, 2005. Registration for the 2006 meeting must be completed online via the ENETS website, www.neuroendocrine.net, and space is filling up fast. The conference will be held 22-24 March, 2006, in one of central Europe's most stunning cities, Prague. Along with our regular fun social program, the Executive Committee of ENETS has planned a valuable line-up of speakers, covering the topics tumor profiling, angiogenesis, receptors and signaling, immunology and vaccination, molecular imaging, and current clinical trials. Please check out the ENETS website for more details, including instructions for the conference's abstract and poster sessions and the preliminary program.

I hope you will find the main feature in this issue of the ENETS Newsletter of great interest. In November, the Society held its first of two consensus meetings on the ENETS Guidelines for the Diagnosis and Treatment of Neuroendocrine Gastrointestinal Tumors. The meeting, which was held in Frascati, outside Rome, attracted 62 scientists from 19 countries. The aim was to scrutinize the Guidelines which were published this year in Neuroendocrinology and which were the focus of this year's annual conference in Cracow. As I write this letter, work has already begun on integrating the valuable comments and expertise of those who attended the meeting. Stay tuned for the promising results to be published soon.

Also in the Newsletter is an interview with my successor, Dr. Wouter de Herder, in which he discusses his plans for ENETS during his tenure as chairman over the next two years.

Bertram Wiedenmann, MD Chairman ENETS 

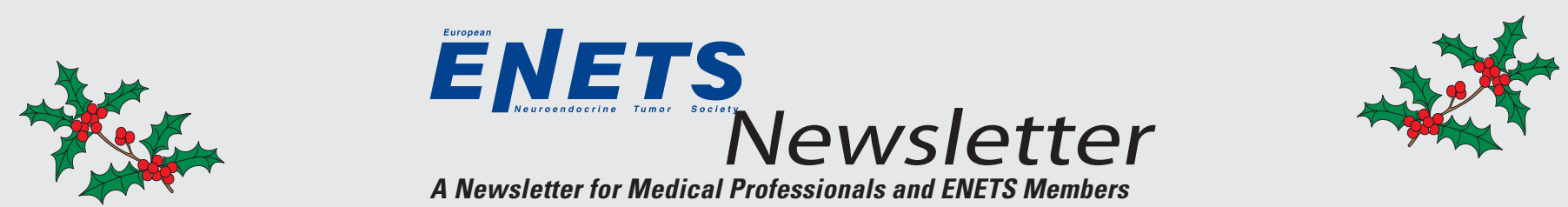

A Newsletter for Medical Professionals and ENETS Members

\section{Consensus Conference on the ENETS Guidelines for the Diagnosis and Treatment of Neuroendocrine Gastrointestinal Tumors}

When the authors of the ENETS Guidelines for the Diagnosis and Treatment of Neuroendocrine Gastrointestinal Tumors published their work earlier this year, they naturally assumed they were not writing the last word on the subject. The Guidelines needed more scrutiny, more expertise, a broader base of international experts' opinions, and, perhaps most importantly, a comprehensive TNM classification for diagnosing and treating neuroendocrine tumor (NET) disease.

The result of this was to be a consensus conference to further examine the Guidelines. Preparations for a November meeting began in the spring of 2005, with the ENETS Executive Committee deciding upon Italy as a good location for the fall. They also developed a list of delegates, with the aim of having the guest list as international as possible, and Guido Rindi, ENETS Vice-Chairman, Parma, Italy, set to work on a preliminary program as well as a workbook of carefully worded questions that would structure the meeting.

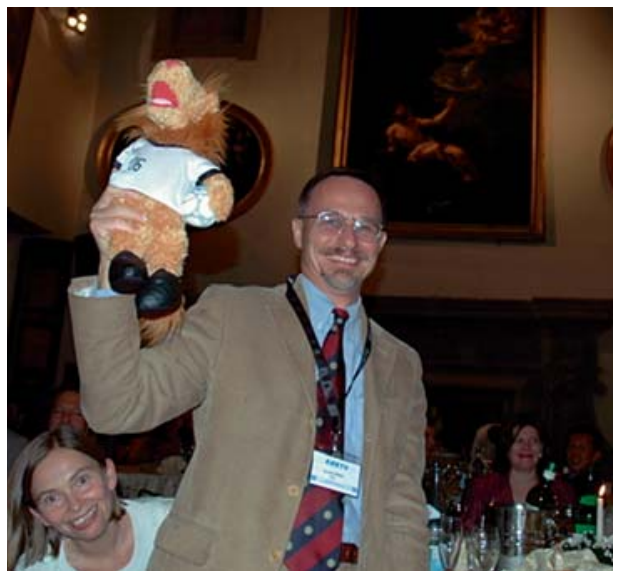

Guido Rindi, Parma, Italy, accepts a warm and cuddly thank-you from ENETS Chairman, Bertram Wiedenmann. Guido Rindi was the local organizer and a driving force in getting the consensus conference off of the drawing board.

This first of two consensus conferences - the second is planned for the fall of 2006 - would focus on foregut tumors and, over two and a half days, the delegates would consider the diagnosis and treatment of well-differentiated gastroduodenal endocrine tumors; well-differentiated pancreatic endocrine tumors, including insulinoma; gastrinoma; and rare functional and nonfunctional pancreatic neuroendocrine tumors, as well as poorly differentiated endocrine carcinomas of foregut origin.

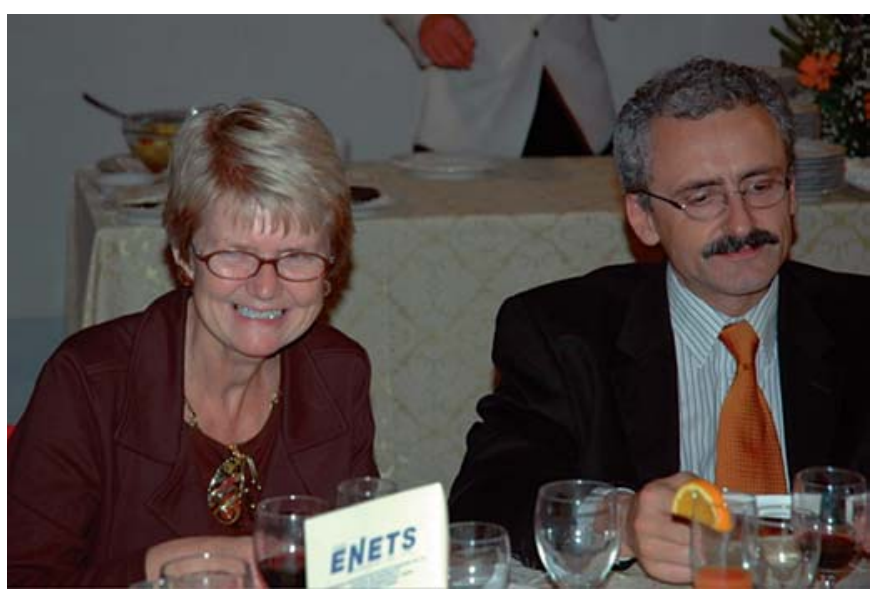

Delegates Babs Taal, Amsterdam, and Paul Komminoth, Baden, Switzerland.

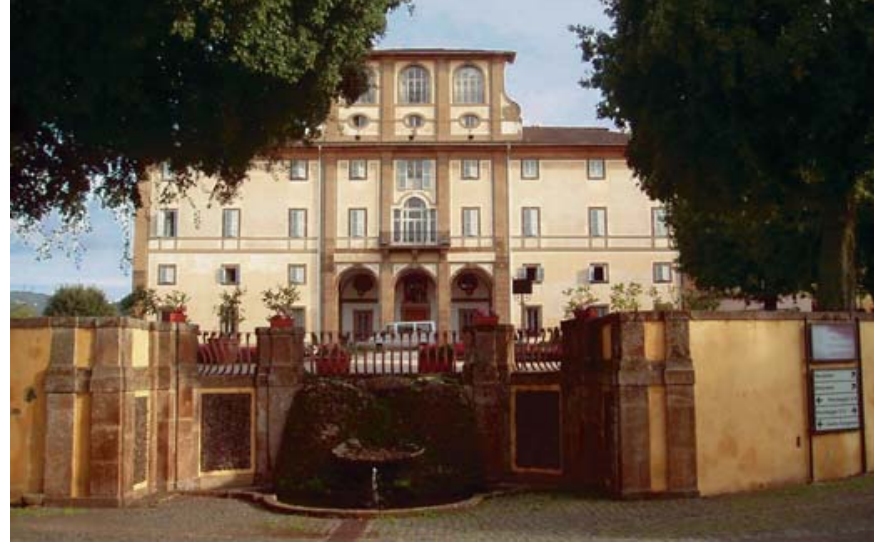

The Hotel Villa Tuscolana provided a quiet and elegant backdrop for the researchers, as they hammered out consensus on the ENETS Guidelines. (Photo: Rudolf Hyrdel)

The conference, which took place 2-5 November at the Hotel Villa Tuscolana in Frascati, outside Rome, had a tightly packed program, with lectures beginning at 8:15 am and the discussion concluding at around 7:00 pm. This meeting was very much hands-on, with all participants requested to volunteer their ideas as often as possible.

Lectures were held by Philippe Ruszniewski and Dermot O'Toole, Clichy, France; Gianfranco Delle Fave, Rome, Italy; Robert Jensen, Bethesda, Md., USA; Wouter de Herder, Rotterdam, The Netherlands; Massimo Falconi, Verona, Italy, and Eric Van Cutsem, Leuven, Belgium. Following the lectures, the delegates were assigned to one of four working groups: imaging, medicine and clinical pathology, pathology and genetics, or surgery. The working groups were tasked with discussing and answering the workbook questions pertaining to their discipline. Once answering the questions, the participants headed back to the main conference room to present their answers to the entire group. Plenty of discussion followed, as notes and responses were transcribed and simultaneously appeared on a screen during the meeting, and, most of the time, the delegates were able to arrive at some consensus, if not during the conference work time, then certainly during the social hour

Special attention during the session was given to reviewing and updating the ENETS Guidelines of 2004 [U. Plöckinger, G. Rindi, R. Arnold, B. Eriksson, E.P. Krenning, W.W. de Herder, A. Goede, M. Caplin, B. Wiedenmann, K. Öberg, J.C. Reubi, O. Nilsson, G. Delle Fave, P. Ruszniewski, H. Ahlman: Guidelines for the Diagnosis and Treatment of Neuroendocrine Gastrointestinal Tumours. Neuroendocrinology 2004;80:394-424]. In particular, statements on incidences, gender distribution, sur-

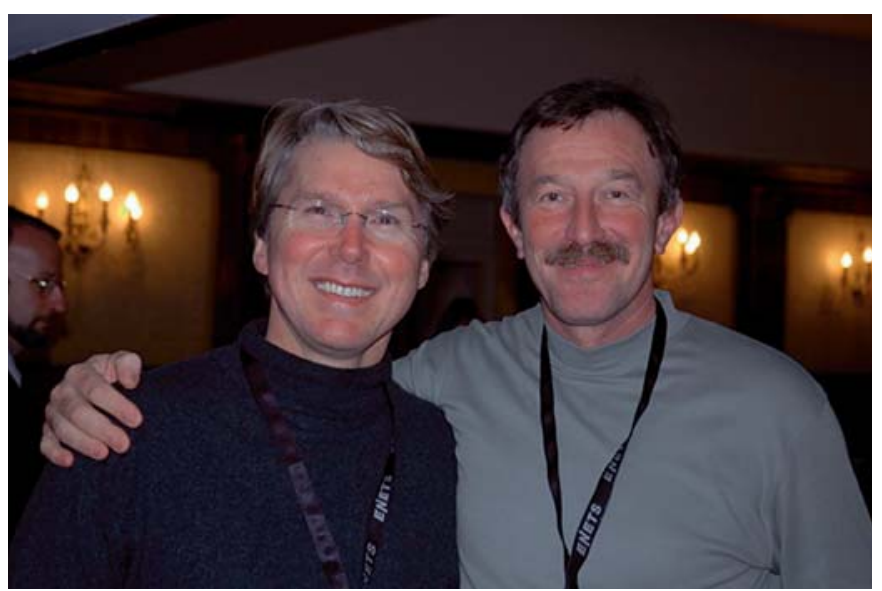

Bertram Wiedenmann and Rudolf Hyrdel, Martin, Slovakia.
KARGER

(c) 2005 S. Karger AG, Basel 
vival, clinical symptoms, diagnostic procedures (especially laboratory evaluation and imaging modalities) and the algorithm of their application, the role of genetic testing and aspects of histopathological workup were considered. The intense discussion among experts in pathology as well as other fields of NET management also led to a common consensus on a TNM classification system for NETs of foregut origin.

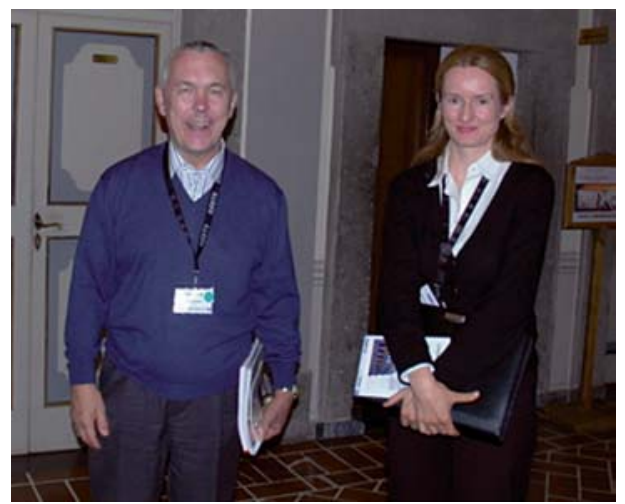

Rudolf Arnold and Marianne Pavel, both of Marburg, Germany, chat during a coffee break.

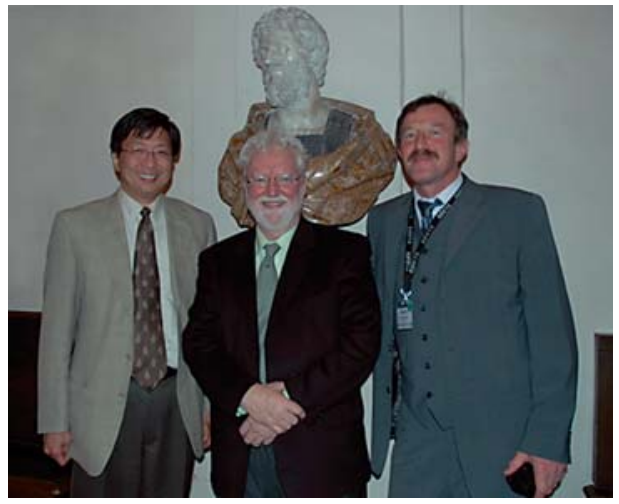

(from left):

Daniel Chung,

Daniel Chung,

Boston, Mass.,

Tampa, Fla., USA

and Rudolf Hyrde

Martin, Slovakia,

pose during the

conference's gala dinner.

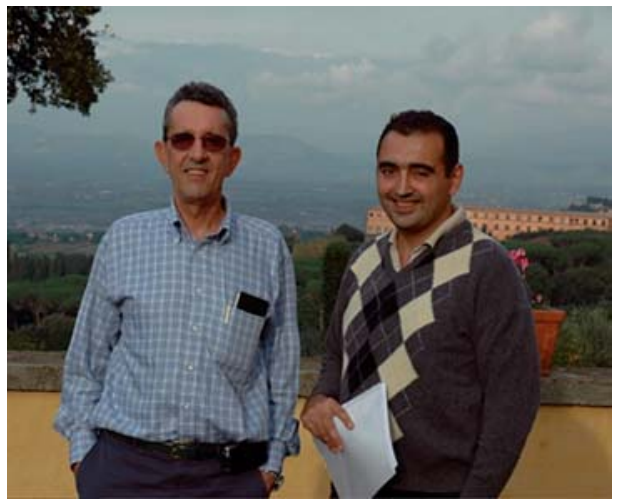

Stanislas Pauwels, Brussels (left) and Ramon Salazar Barcelona, during a coffee break.

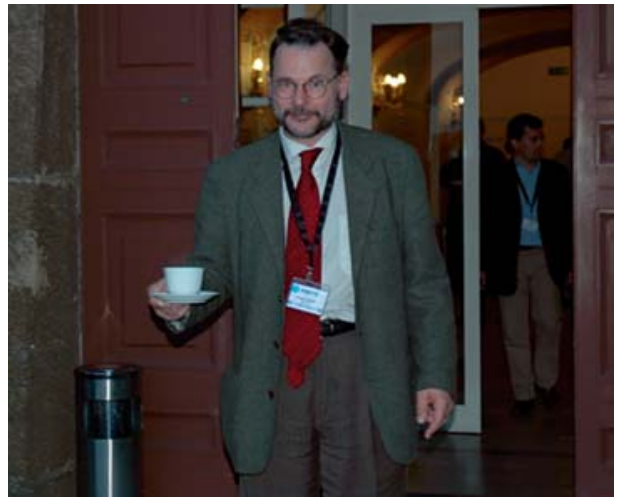

Anders Sundin Uppsala, Sweden heads out for some fresh air during a coffee break.
Surgical procedures for curative surgery and criteria for decision-making were agreed upon by the surgical group, as well as surgical and interventional treatment options for irresectable and/or metastatic disease. Medical treatment options in palliative care, with a special focus on somatostatin analogs and interferon therapy, as well as chemotherapeutical options, were discussed intensely. This discussion also highlighted the necessity of controlled clinical trials in the future to better validate the treatment options for NETs. The role of peptide-receptor-guided radionuclide therapy was also considered carefully for each of the discussed tumor entities. Finally, common follow-up strategies were agreed upon.

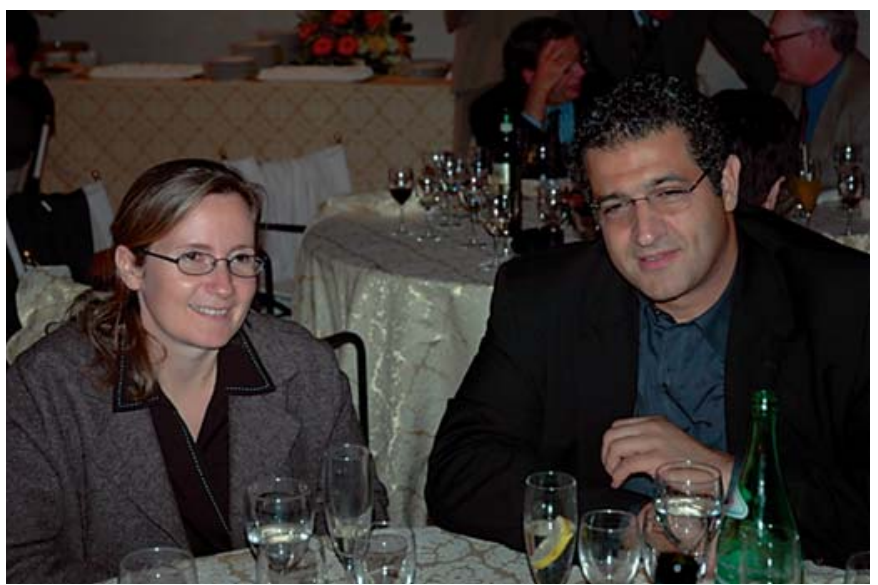

Anne Couvelard, Clichy, and Riaz Kianmanesh, Colombes, France.

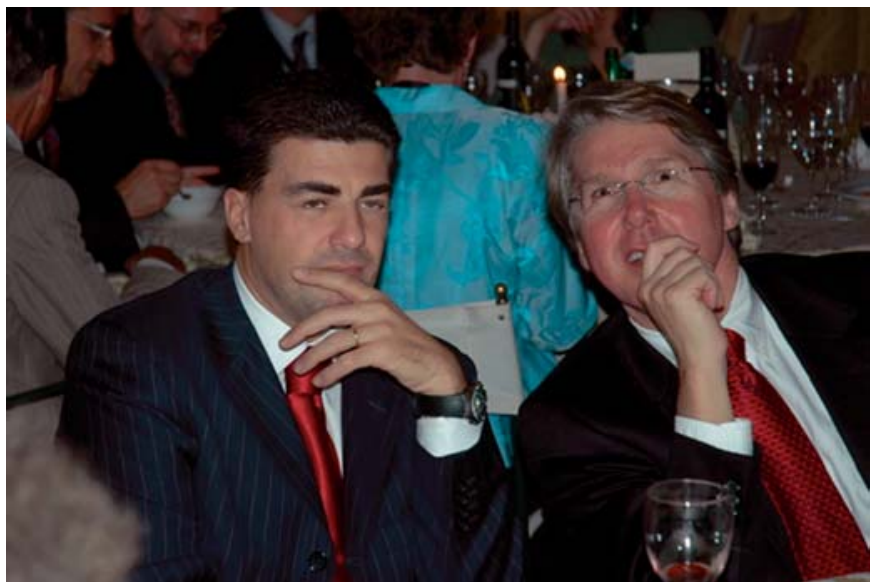

Pasquale Frega of Beaufour Ipsen Pharma, a generous supporter of the consensus conference, with Bertram Wiedenmann.

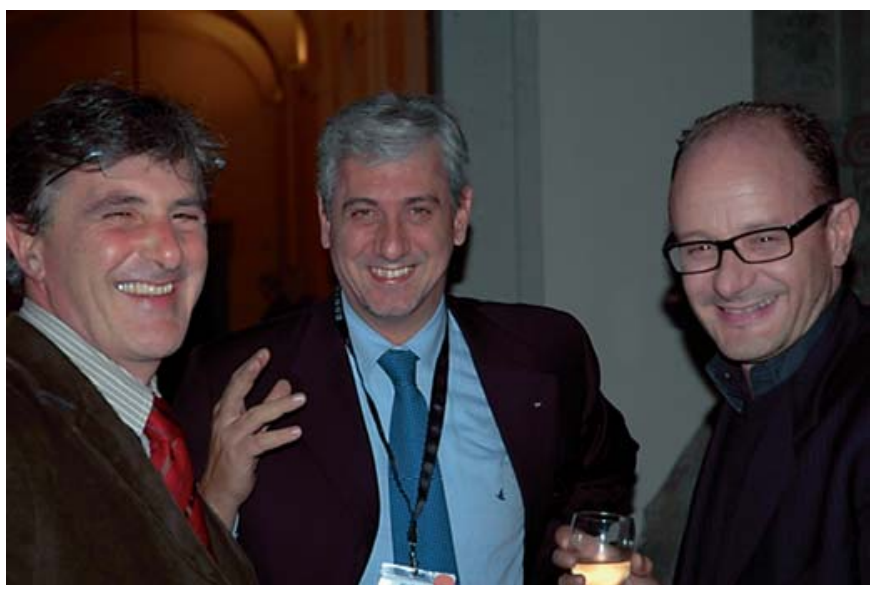

La dolce vita ... Aldo Scarpa and Massimo Falconi, both of Verona, and Diego Ferone, Genoa, Italy. 
On the Friday of the conference, the delegates were taken to the Palazzo Chigi di Arricia, a 17th-century Baroque palace designed by Gian Lorenzo Bernini. The palazzo today houses a number of neoclassical works of art and furniture, including an antique wheelchair and delicate leather wall coverings and paintings. Highly rated were the old pharmacy and a room filled with 17 paintings of individual nuns, all daughters of one of the princes who resided at the palace. Over dinner and drinks, as well as a giant cake emblazoned with ENETS across it, delegates let go of the day's work and enjoyed the ambiance of a pleasant Italian fall evening. A special toast was given to IPSEN's Pasquale Frega who generously supported the idea and concrete planning of a consensus meeting for the Guidelines.

Work remains beyond the conference. Integrating the answers and comments given by all of the participants is at the heart of improving the current Guidelines. Stay tuned for that and more, and should any ENETS member like to obtain the conference program, please contact the ENETS Coordinating Office at the address on the front of the Newsletter.

Elizabeth Zach, Ulrich-Frank Pape

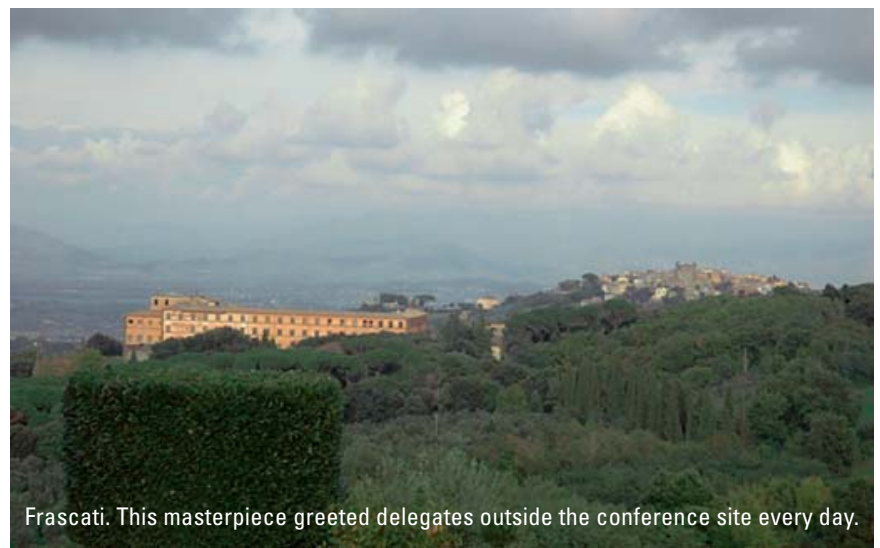

\section{Meet the New Chairman: Wouter W. de Herder Takes Over ENETS Chairmanship in March 2006}

Wouter W. de Herder, currently ENETS' Chairman Elect, will take over as chairman of the European Neuroendocrine Tumor Society (ENETS) in March 2006. Dr. de Herder is a consultant endocrinologist at the Erasmus MC in Rotterdam. His major research interests are neuroendocrine and adrenal tumors/Cushing's syndrome. He is a member of several international and Dutch national societies, such as the Dutch Society for Endocrinology, the Endocrine Society (USA), the Society for Endocrinology (UK), and the Pituitary Society (USA). He has published numerous peer-reviewed papers, is a reviewer for many international and national journals, and regularly presents at both Dutch and international conferences. Here, he answers questions about what lies ahead in the coming two years of his chairmanship.
A main goal of ENETS so far has been to develop guidelines for treating NET disease. Guidelines were published this year, and the first of two consensus meetings held in November. What are the next steps?

There will be a follow-up meeting on the recent ENETS Guidelines meeting which was held in Frascati. This follow-up meeting will deal with Guidelines for NETs of midgut and hindgut origin. Meanwhile, the different national networks are working on national guidelines.

Another goal of ENETS has been to educate physicians and researchers in the study of NET disease. Aside from the Society's annual conferences, how can ENETS achieve this goal?

There are different ways to accomplish this. Publications are important. So are educational courses for residents as well as postgraduate courses. Investigators' meetings and Web-based systems are also a priority.
What do you think are some of the best accomplishments of ENETS?

ENETS is the first international forum for physicians, dealing with neuroendocrine tumor (NET) patients. Up to now, there has been no such organization. Instead, the disciplines gastroenterology, oncology, endocrinology, surgery, and radiology, and specialists like for the pancreas, had their own meetings where diagnostic and treatment issues were amply discussed, but no common strategy could be achieved, and thus no common guidelines for treatment and diagnosis could be developed. ENETS unites the disciplines, and it is the perfect forum to develop expertise in the field of NET research. The ENETS Guidelines are an example of this.

What are the challenges ahead for the Society?

In my opinion, ENETS will have to advance from a European towards an international organization in order to really collect opinions and research activities in the international medical and science community. This should be of great benefit to all patients, physicians, and scientists in terms of patient management and networking research activities. Furthermore, only an international society will have the authority to represent the interests of the NET field to politicians and healthcare providers which is an important issue for the future in these times of restricted public health care resources. Another challenge is that in many countries outside Western Europe and the USA physicians have just recently started recognizing NET disease. As an example, somatostatin analogs are still not registered for the control of hormonal symptoms caused by functional NETs.

Your chairmanship lasts two years. What do you hope to bring to ENETS during that time?

I hope that ENETS will become an even more broadly recognized international forum for doctors dealing with NET patients, that ENETS will be capable of networking research activities in the basic and clinical sciences area, and that ENETS will continue to be a partner for patient interest groups.

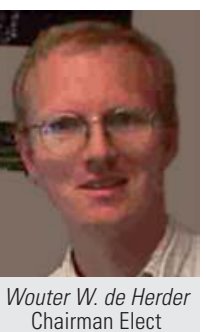

ENETS has grown steadily from about 200 members to nearly 300 in the past year. What attracts members to ENETS, and how can the Society continue to increase membership?

Members recognize that ENETS is the only society for physicians dealing with NET. The number of members will hopefully further increase, especially as ENETS evolves into an international organization.

Following the 2nd Annual Educational Conference in Cracow in spring, one ENETS member who attended commented afterward that ENETS needs to be 'more open and transparent'. How would you respond to this member's comment?

One response is to have more members be invited to participate in the task forces. Another way can be that the national networks should send representatives to the task forces and also to be considered being placed on the ENETS Advisory Board. Members can and should also inquire about becoming representatives to the Executive Committee. A European organization like the EFES (European Federation of Endocrine Societies) works like that With regard to transparency: We try to communicate as much as possible via this Newsletter and the ENETS website. But remember that ENETS is still a very young organization. It was founded in 2004, and so I would say we are still in a foundational phase.

The Executive Committee of ENETS would like to establish an advisory board for the Society. What do you see as the role of such a board?

The Advisory Board will be a group of experts in the NET field who can help the Executive Committee solve some of the issues that arise during the board meetings. Also, the Advisory Board can start initiatives on future activities of ENETS in cooperation with the Executive Committee, and it will represent specialists from most European countries, so that individual national aspects will also be considered where appropriate. 